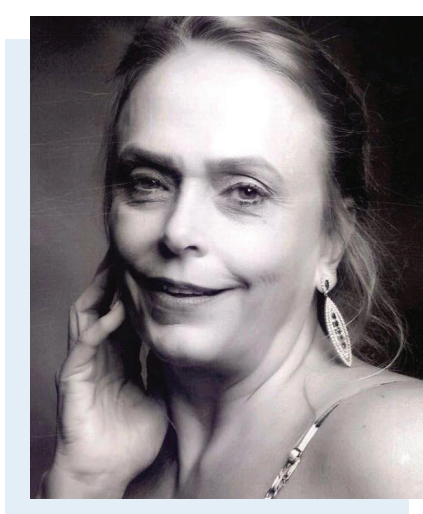

\title{
Enfermagem: percurso e possibilidades
}

\author{
Nursing: journey and possibilities
}

Enfermería: recorrido y posibilidades

Maria Angela Boccara de Paula

ORCID ID

Paula MAB (D) https://orcid.org/0000-0002-7438-9595

COMO CITAR

Paula MAB. Enfermagem: percurso e possibilidades. ESTIMA, Braz. J. Enterostomal Ther., 16: e2818. https://doi.org/10.30886/ estima.v16.657_PT

Falar sobre enfermagem é falar de muitas possibilidades e oportunidades que estão presentes no cotidiano dos profissionais, pois fazer enfermagem envolve conhecimento, ética, responsabilidade, comunicação e, especialmente, partilha.

Cuidar é a essência do profissional de enfermagem, que realiza sua prática profissional em diferentes espaços, da comunidade ao hospital especializado, representando a maior força de trabalho no campo da saúde no Brasil e no mundo. É o profissional sempre presente nas 24 horas do dia, atuando diretamente no cuidado.

É uma profissão que transcende o fazer puramente técnico, que envolve o profissional que precisa desenvolver diferentes competências, como a "competência prática", por meio da qual desenvolve o que foi planejado, buscando alcançar os melhores resultados; a "competência intuitiva”, aquela que o profissional usa quando percebe além de seu tempo e espaço, buscando, sempre que possível, novas e diferenciadas alternativas para seu trabalho, sendo que para isso é preciso também ter ousadia; a "competência intelectiva”, que demanda análise e muita reflexão; e, principalmente, a "competência emocional", uma competência de "leitura de alma", devendo existir em seu trabalho grande apelo aos afetos, o que gera sintonia e propicia a empatia ${ }^{1}$.

Cuidar é seu objeto de trabalho. E cuidar é complexo: engloba multiplicidade de ações, é estar atento, coerente e harmônico de forma a propiciar, para aquele que necessita desse cuidado, segurança, uma vez que o processo saúde-doença envolve incertezas, medos e, muitas vezes, mudanças temporárias ou definitivas.

Assim, o profissional de enfermagem vivencia, diariamente, situações que demandam habilidades para ser capaz de agir imediatamente ou apenas esperar e vigiar, sendo assim uma grande possibilidade de construção e reconstrução, invenção e reinvenção, numa racionalidade 
que não pode se esgotar, mas que precisa se renovar a cada momento, para que seja possível desenvolver seu trabalho de forma coerente com a realidade e, principalmente, de forma integrada com os demais membros da equipe de saúde.

Dessa forma, o trabalho dos profissionais precisa acontecer em consonância e harmonia com os outros profissionais que atuam no campo da saúde, visando prestar assistência de qualidade às pessoas que dela necessitem. Assim, o trabalho interdisciplinar se faz essencial, o que é desafiador também, pois interdisciplinaridade é "atitude", é ação em movimento e, segundo Fazenda ${ }^{1}$, essa, acoplada às dimensões advindas da prática em situação real e contextualizada, o que nem sempre é simples ou fácil, demanda atenção e vontade, pois a troca com outros saberes e a saída do anonimato exigem do profissional de enfermagem especial postura teórica e ética, que por vezes demanda apresentações cautelosas e, com frequência, paciência e espera, pois nem sempre suas opiniões são consideradas ou acatadas por outros profissionais que atuam na equipe multidisciplinar.

Assim, o ensino da enfermagem também é um grande desafio, vez que o conhecimento se amplia com rapidez, assim como o desenvolvimento tecnológico. $O$ professor enfermeiro não apenas identifica os aspectos próprios referentes ao conhecimento do homem biológico, mas sabe que esse conhecimento não se esgota na dimensão física e técnica e vivencia a necessidade de conduzir o processo ensino-aprendizagem em enfermagem por outras dimensões que não apenas as concretas ou racionais, como, por exemplo, a dimensão simbólica e emocional, para que, dessa forma, esteja mais apto também para analisar os processos, a afetividade, o efeito da força e a força dos efeitos, as dimensões sociais e institucionais, as estratégias organizacionais e, principalmente, a articulação desses saberes efetivados na prática cotidiana do cuidar.

E, dessa forma, a pesquisa em enfermagem é mandatória e, felizmente, cada vez mais, enfermeiros se dedicam a esse campo, buscando investigar e contribuir para a construção de conhecimentos teóricos e práticos que possam ser úteis à humanidade, exercitando, também, formas interdisciplinares de teorizar e, principalmente, praticar.

Outros campos de trabalho também ganham espaço na contemporaneidade para o enfermeiro e sua equipe. Dentre eles destacam-se a auditoria, o marketing, a assessoria técnica dentre outros.

Múltiplos saberes tornam-se essenciais para o cuidado, contribuindo para o desenvolvimento da enfermagem especializada. Assim, a enfermagem gradativamente vem ocupando os espaços e se faz presente em diferentes campos de atenção à saúde, da assistência direta à indireta, mostrando que o profissional de enfermagem é "essencial e único" e merece ser devidamente reconhecido pelo seu importante papel social.

Afirmo que quando se compreende a ambiguidade que nosso corpo contempla, passamos a aprimorar a capacidade de lidar com o outro, com o mundo, resgatando, assim, o sentido do nosso trabalho e da vida, por meio da experiência vivida, num exercício de tolerância e de humildade próprio de uma generosidade que inaugura a enfermagem de ontem, hoje e do amanhã.

\section{REFERÊNCIAS}

1. Fazenda ICA. Dicionário em construção: interdisciplinaridade. 2a. ed. São Paulo: Cortez; 2001. 